\title{
KAJIAN ETNOBOTANI BUDAYA NGALAKSA DI KECAMATAN RANCAKALONG KABUPATEN SUMEDANG
}

\author{
Yuna Islamiati $^{1 *}$, Nisrina Khairun Nisa ${ }^{1}$, Restu Anugrah ${ }^{1}$, Triska Rosma ${ }^{1}$, Tri \\ Cahyanto 1 \\ ${ }^{1}$ Jurusan Biologi, Fakultas Sains dan Teknologi, Universitas Islam Negeri Sunan Gunung \\ Djati, Bandung \\ *e-mail: yunaislamiati_yun@yahoo.com
}

diterima: 3 Desember 2019; direvisi: 15 Januari 2020; disetujui: 2 Februari 2020

\begin{abstract}
ABSTRAK
Masyarakat Rancakalong masih memegang teguh kebudayaan setempat. Umumnya, masyarakat Rancakalong bermata pencaharian sebagai petani sawah. Hal ini membawa masyarakat Rancakalong melakukan budaya ngalaksa sebagai rasa syukur terhadap kemakmuran melalui hasil padi yang dilambangkan sebagai Dewi Sri. Penelitian ini bertujuan untuk mengkaji secara etnobotani yang digunakan dalam budaya ngalaksa di Kecamatan Rancakalong. Metode yang digunakan adalah deskriptif eksploratif dengan teknik pengumpulan data yaitu Purposive Random Sampling dan Snowball Sampling. Budaya ngalaksa sangat erat hubungannya dengan kajian etnobotani karena menggunakan padi (Oryza sativa L.) sebagai bahan utama serta penggunaan tumbuhan lain berupa kecombrang (Etlingera elatior (Jack) R.M.Sm), congkok (Curculigo orchioides Gaertn), cariang (Colocasia esculenta (L.) Schott) dan kelapa (Cocos nucifera L.). Tumbuhan tersebut sangat dibutuhkan dalam jumlah yang banyak dan tidak dapat digantikan oleh tumbuhan lain.
\end{abstract}

Kata Kunci: Etnobotani, Ngalaksa, Oryza sativa, dan Rancakalong

\section{STUDY ETHNOBOTANY OF NGALAKSA CULTURE AT RANCAKALONG SUB- DISTRICT SUMEDANG DISTRICT}

\begin{abstract}
The Rancakalong People still hold tight the local culture. Generally, the Rancakalong people are living as farmer. This matter makes the Rancakalong people do the culture of Ngalaksa. This cultural purpose is gratitude of prosperity throught the rice harvest symbolized as Dewi Sri. The purpose of this research is to examine ethnobotany of plants that used in Ngalaksa culture at Rancakalong Sub-district. The method of this research uses descriptive-exploration with the technique of data collection is Pusposive Random Sampling and Snowball Sampling. Ngalaksa culture relates with ethnobotany studies because it uses rice (Oryza sativa L.) as the main plant and other plants such as kecombrang (Etlingera elatior (Jack) R.M.Sm), congkok (Curculigo orchioides Gaertn), cariang (Colocasia esculenta (L.) Schott) and coconut (Cocos nucifera L.). These plants are needed in large quantities and cannot be replace by other plants.
\end{abstract}

Key words: Ethnobotany, Ngalaksa, Oryza sativa, and Rancakalong 


\section{PENDAHULUAN}

Masyarakat Rancakalong sangat mempertahankan kebudayaan setempat dan umumnya bermata pencaharian sebagai petani padi. Sehingga proses penanamannya masih kental dengan budaya mereka. Salah satu kebudayaan masyarakat Rancakalong adalah Ngalaksa. Ngalaksa berarti membuat kue laksa berjumlah sepuluh ribu buah. Kue laksa adalah makanan berupa lontong yang dibungkus daun congkok (Komarudin, 2016). Ngalaksa ini merupakan proses pasca panen, diantaranya yaitu bewara (musyawarah), mera (pembagian bahan), meuseul (menumpuk padi), ngawasuhan (mencuci beras), ngineb (menyimpan beras), numbuk (menumbuk beras menjadi tepung), membuat laksa (mengadoni tepung), dan membuat orok-orokan (mengecet laksa)(Komarudin, 2016). Pelaksanaan budaya ngalaksa dilakukan oleh lima rurukan di kecamatan Rancakalong, diantaranya Desa Rancakalong, Desa Cibunar, Desa Nagarawangi, Desa Pasirbiru, dan Desa Pamekaran (Isnendes, 2013).

Budaya Ngalaksa di Rancakalong merupakan wujud penghormatan terhadap Dewi Sri dengan tujuan supaya masyarakat Rancakalong diberi kemakmuran melalui padi (Andriansyah, 2012). Dewi Sri yang menjadi sebuah mitos bagi masyarakat diceritakan bahwa kematiannya memberikan kemakmuran dengan tumbuhnya tumbuhan pangan yaitu padi di atas kuburnya. Padi yang tumbuh tersebut terbagi menjadi tiga bagian yaitu cikal berupa padi pada lahan kering, panengah berupa padi pada lahan genangan air, dan padi muda yang tumbuh pada lahan kering maupun lahan genangan air (Isnendes, 2019)

Budaya Ngalaksa sangat berkaitan dengan kajian etnobotani. Bahan dan proses pembuata laksa sendiri menggunakan bahan-bahan alam terutama tumbuhan. Tujuan dilakukan penelitian ini adalah untuk mengkaji secara etnobotani tumbuhan yang digunakan dalam budaya Ngalaksa di Kecamatan Rancakalong.

\section{BAHAN DAN METODE}

Penelitian dilakukan pada bulan September sampai dengan Oktober 2019. Lokasi penelitian yaitu Kecamatan Rancakalong, Kabupaten Sumedang, Provinsi Jawa Barat (Gambar 1.) Luas wilayah Kecamatan Rancakalong adalah $52,28 \mathrm{~km}^{2}$ dengan jumlah 10 desa dan total jumlah penduduk sebanyak 39.094 jiwa (BPS Kabupaten Sumedang, 2018). Penelitian ini hanya dilakuan pada 5 desa, yaitu Desa Nagarawangi, Cibunar, Rancakalong, Pasir Biru, dan Pamekaran, karena menyesuaikan dengan desa yang melaksanakan budaya Ngalaksa.

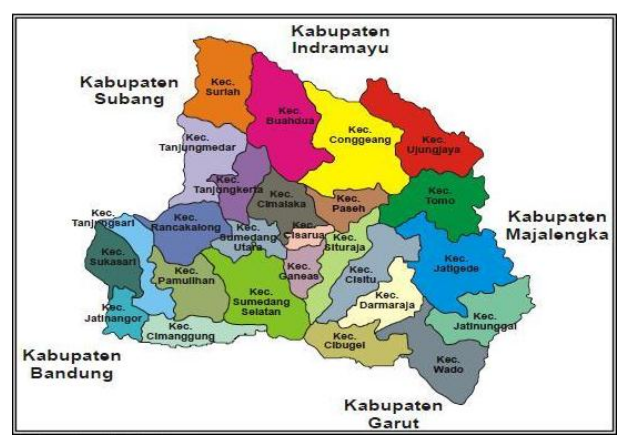

Gambar 1. Peta Administratif Kabupaten Sumedang (Sumber: PBS Kabupaten

Sumedang, 2018)

Alat yang digunakan dalam penelitian ini adalah alat tulis, perekam dan perangkat pengolah kata. Metode yang digunakan adalah deskriptif-ekploratif dengan teknik pengumpulan data yaitu wawancara semi terstruktur. Wawancara dilakukan kepada 30 orang masyarakat Rancakalong. Hal ini sejalan dengan sampel yang layak dijadikan penelitian yaitu 30 sampai 500 orang (Sugiyono, 2007). Sumber wawancara menggunakan metode purposive random sampling yang ditentukan secara terpilih (Setiawan \& Qiptiyah, 2014) dan snowball sampling yang direkomendasikan oleh informan dkk., 2016). Sumber yang ditetapkan yaitu ketua rurukan, tokoh adat dan masyarakat secara acak. Wawancara dilakukan kepada ketua rurukan kecamatan Rancakalong yaitu Bapak Oman Sutisna dari Desa Nagarawangi. Informasi lebih lanjut didapatkan dari tokoh adat 
diantaranya Bapak Oting Laksa sebagai pembuat laksa, Bapak Yono sebagai Nayaga (pemain seni tarawangsa), Abah Oting sebagai pemain seni tarawangsa, Ema Idah sebagai penari seni tarawangsa, dan Bapak Susilo sebagai Ketua RW 6 Desa Rancakalong serta dilakukan wawancara kepada masyarakat terpilih lainnya.

\section{HASIL DAN PEMBAHASAN Proses Ngalaksa}

Ngalaksa merupakan proses pembuatan kue laksa. Laksa merupakan makanan seperti lontong yang dibungkus dengan daun congkok (Gambar 2.). Rasa laksa sangat khas yaitu pahit dan asam.

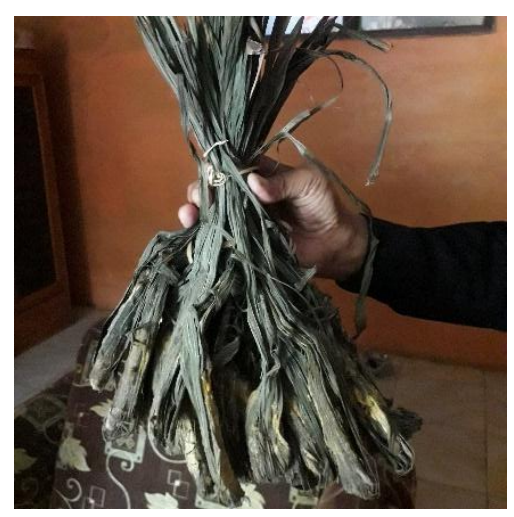

Gambar 2. Laksa yang dibuat pada Juli 2019

Proses ngalaksa dilakukan pada bulan Juli atau yang ditetapkan oleh tokoh adat selama tujuh hari tujuh malam. Proses ngalaksa diawali dengan bewara (musyawarah), dilanjutkan mera (pembagian), meuseul (menumbuk), ngisikan/nyiraman (mencuci), ngineb (disimpan), meuseul geulis (menumbuk jadi tepung), ngadonan (diadoni dengan bumbu dan dibungkus), kemudian direbus. Terdapat satu proses yang sudah tidak dilakukan yaitu membuat orok-orokan kemudian digencet sebelum masuk pada proses perebusan. Proses tersebut tidak dilakukan karena tidak ada orang/bagian ahli yang melakukan proses tersebut.

Padi yang dikumpulkan saat bewara hingga mencapai dua kwintal kemudian dilakukan mera (pembagian) untuk dibawa ke Desa Rancakalong sebagai tempat upacara ngalaksa. Padi tersebut kemudian disimpan dari hari Minggu hingga Kamis. Pada hari Kamis, dilakukan proses meuseul yaitu padi ditumbuk untuk mendapat beras dan dicuci dengan air khusus dari mata air Citumbal. Selanjutnya beras diineb (disimpan) di goah/pajemuhan dengan alas dan penutup dari daun cariang serta dilakukan penyiraman menggunakan air kecombrang secara berkala selama 3 hari. Pada hari Minggu, beras ditumbuk menjadi tepung (meuseul geulis) dan diadoni menggunakan bumbu (garam, kelapa dan air kapur sirih), Selanjutnya adonan dibungkus dengan daun congkok dan diikat sebanyak 20 hingga 50 laksa. Laksa kemudian direbus di tempat pembakaran dengan tungku dari pangkal batang pisang hingga masak. Laksa yang telah jadi dapat dicicipi dan dibagi kepada masyarakat sebanyak satu ikat padi (gedeng/geugeus) atau $5 \mathrm{~kg}$.

Tabel 1. Tumbuhan yang digunakan dalam budaya Ngalaksa

\begin{tabular}{|c|c|c|c|c|c|}
\hline \multicolumn{3}{|c|}{ Tumbuhan } & \multirow{2}{*}{ Bagian } & \multirow{2}{*}{ Fungsi } & \multirow{2}{*}{$\begin{array}{c}\text { Cara } \\
\text { memperoleh }\end{array}$} \\
\hline Nama lokal & Nama ilmiah & Famili & & & \\
\hline Padi ranggeuyan & Oryza sativa $\mathrm{L}$. & Poaceae & Biji & Bahan utama laksa & Ditanam \\
\hline Kecombrang & $\begin{array}{l}\text { Etlingera elatior } \\
\text { (Jack) R.M.Sm. }\end{array}$ & Zingiberaceae & Seluruhnya & $\begin{array}{l}\text { Nyiraman padi } \\
\text { (membersihkan) }\end{array}$ & Ditanam \\
\hline Congkok & $\begin{array}{l}\text { Curculigo } \\
\text { orchioides Gaertn. }\end{array}$ & Liliaceae & Daun & Pembungkus & $\begin{array}{l}\text { Mengambil } \\
\text { dari hutan }\end{array}$ \\
\hline Cariang/talas & $\begin{array}{l}\text { Colocasia esculenta } \\
\text { (L.) Schott }\end{array}$ & Araceae & Daun & $\begin{array}{l}\text { Alas dan penutup } \\
\text { laksa }\end{array}$ & $\begin{array}{l}\text { Mengambil } \\
\text { dari hutan }\end{array}$ \\
\hline Kelapa & Cocos nucifera L. & Arecaceae & Daging buah & Bumbu & Pasar \\
\hline
\end{tabular}




\section{Tumbuhan yang Digunakan dalam Budaya Ngalaksa}

Berdasarkan penelitian yang telah dilakukan terhadap kajian etnobotani budaya ngalaksa di Kecamatan Rancakalong didapatkan bahwa tumbuhan yang digunakan sebanyak 5 spesies yaitu padi (Oryza sativa L.), kecombrang (Etlingera elatior (Jack) R.M.Sm), congkok (Curculigo orchioides Gaertn), cariang (Colocasia esculenta (L.) Schott) dan kelapa (Cocos nucifera L.) (Tabel 1.). Tumbuhan utama yang digunakan dalam budaya ngalaksa adalah padi (Oryza sativa L.). Tumbuhan lainnya yang digunakan adalah kecombrang (Etlingera elatior (Jack) R.M.Sm) yang diambil air perasan, daun congkok (Curculigo orchioides Gaertn) sebagai pembungkus laksa, daun cariang (Colocasia esculenta (L.) Schott) sebagai alas dan penutup laksa pada proses ngineb, serta daging buah kelapa (Cocos nucifera L.) sebagai bumbu dari laksa.
Padi yang digunakan adalah padi khusus kultivar padi ranggeuyan/ageung ceresisi maupun hawara (Gambar 3). Padi ranggeuyan ceresisi memiliki ciri yaitu tidak memiliki ekor pada ujung bulir dan gabah, permukaan berasnya tidak memiliki zat perekat (glutinous), gabah tidak mudah rontok, hawara/tumbuh cepat (4-5 bulan). Sedangkan padi ranggeuyan hawara memiliki ciri yaitu memiliki ekor pada ujung bulir dan gabah, padi biasa yang tidak memiliki zat perekat, gabah tidak mudah rontok, leuir/tumbuh lama (5-6 bulan) (Irawan \& Purbayanti, 2008). Penanaman padi ranggeuyan pada sawah yang tergenang air dan dapat dipanen setelah 3-4 bulan. Padi tersebut ditanam oleh masyarakat Rancakalong, khususnya oleh tokoh adat yang diperuntukkan acara adat. Penanaman padi ranggeuyan ini semakin berkurang karena sulitnya pengolahan pasca panen yang membutuhkan tenaga lebih kuat dalam merontokkan gabah.

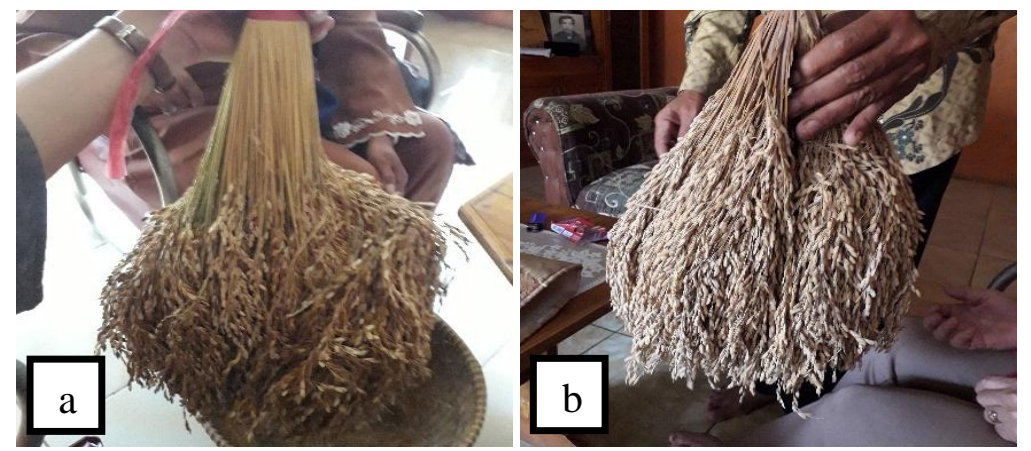

Gambar 3. Padi ranggeuyan ceresisi (a) dan hawara (b) (Dok. Pribadi, 2019)

Bahan-bahan tumbuhan untuk budaya Ngalaksa di dapat secara mudah di alam. Padi ranggeuyan digunakan seluruh bagiannya pada prosesi budaya Ngalaksa, namun hanya biji padi berupa beras yang digunakan dalam membuat laksa. Padi ranggeuyan diperoleh dari masyarakat dengan cara gotong royong sehingga didapatkan padi hingga lebih dari dua kwintal. Kecombrang (Etlingera elatior (Jack) R.M.Sm) digunakan dalam menyiram padi selama diineb (simpan) untuk membersihkannya, sehingga didapatkan rasa asam. Kecombrang mengandung senyawa alkaloid, flavonoid, poliferol, steroid, saponin, dan minyak atsiri sebagai antimikroba sehingga dapat digunakan sebagai pengawet makanan melalui proses fermentasi (Naufalin \& Rukmini, 2014). Kecombrang diperoleh langsung di tempat wisata/pengolahan laksa karena dibudidayakan sebagai tanaman hias. Daun congkok (Curculigo orchioides Gaertn) diperoleh dari hutan sekitar Rancakalong dengan jumlah 10 hingga 20 ribu daun untuk membungkus laksa. Daun Cariang (Colocasia esculenta (L.) Schott) didapatkan dari hutan juga pemukiman warga karena dapat tumbuh dengan mudah. 
Jumlah bahan yang dibutuhkan sangat banyak dan tidak dapat digantikan oleh tumbuhan lain. Bahan yang akan digunakan dalam budaya Ngalaksa sudah seharusnya diperoleh dengan tidak mengurangi esensi dan tujuan dari budayanya itu sendiri. Tumbuhan yang dibutuhkan sangat mudah didapat baik di alam maupun hasil budidaya, terutama padi sebagai pangan pokok manusia. Tidak menutup kemungkinan bahwa bahan lain akan sulit didapat karena kebutuhan yang banyak sehingga perlu adanya pembudidayaan.
Bahan pengiring selalu disertakan pada upacara Ngalaksa yang ditunjukkan pada Gambar 4. Bahan pengiring tersebut diantaranya adalah alat yang digunakan dalam proses ngalaksa secara tradisional, berupa beubeutian (ubi dan buah), serta sesajen. Namun bahan pengiring tidak termasuk pada laksa itu sendiri. Tradisi ini diiringi pula dengan seni yang dimainkan dalam proses ngalaksa yaitu seni tarawangsa.

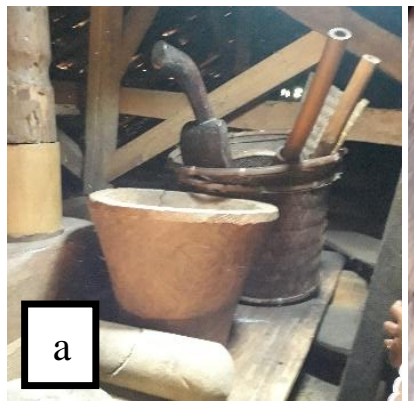

Gambar 4. Pengiring Upacara Ngalaksa (a) alat-alat, (b) sesajen, (c) alat musik tarawangsa (Dok.pribadi, 2019)

\section{Pengetahuan Budaya Ngalaksa}

Berdasarkan 30 orang yang diwawancarai secara terpilih, sebanyak 6 orang sebagai informan kunci dan 24 warga di Kecamatan Rancakalong. Pengetahuan budaya Ngalaksa bagi masyarakat Rancakalong dapat dikelompokkan dslsm tingkatan (Gambar 5).

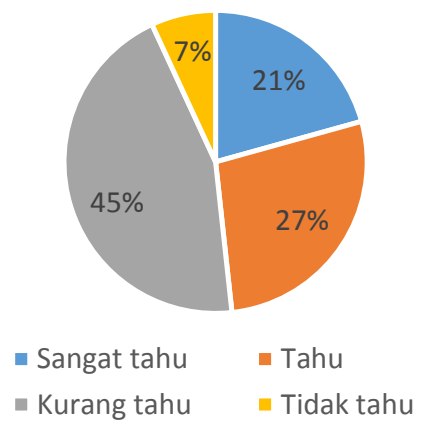

Gambar 5. Persentase tingkat pengetahuan masyarakat Rancakalong terhadap budaya Ngalaksa
Berdasarkan gambar 5 bahwa persentase terbesar sebanyak $45 \%$ memiliki pengetahuan yang kurang terhadap budaya Ngalaksa, sebanyak $27 \%$ mengetahui. Jumlah pengetahuan dengan tingkat mengetahui terbagi melalui partisipasi masyarakat dalam mengikuti atau melihat budaya ngalaksa dan melalui cerita masyarakat. Persentase $21 \%$ merupakan tingkat pengetahuan sangat tahu berdasarkan informan kunci yaitu ketua rurukan dan tokoh adat. Sedangkan pengetahuan masyarakat pada tingkat tidak tahu sebanyak 7\% karena masyarakat tidak ikut andil serta acuh tak acuh terhadap budaya Ngalaksa.

Pengetahuan masyarakat terhadap budaya Ngalaksa dirasa minim, khususnya pada tahap proses pembuatan dan tujuan Ngalaksa. Hal ini disebabkan budaya Ngalaksa merupakan budaya yang tidak dapat dilakukan oleh sembarang orang, yaitu hanya dilakukan oleh keturunan para leluhur yang melaksanakan budaya Ngalaksa. 
Dengan demikian informasi yang diinginkan harus tepat agar terhindar dari informasi yang menyesatkan akibat perbedaan persepsi setiap orang.

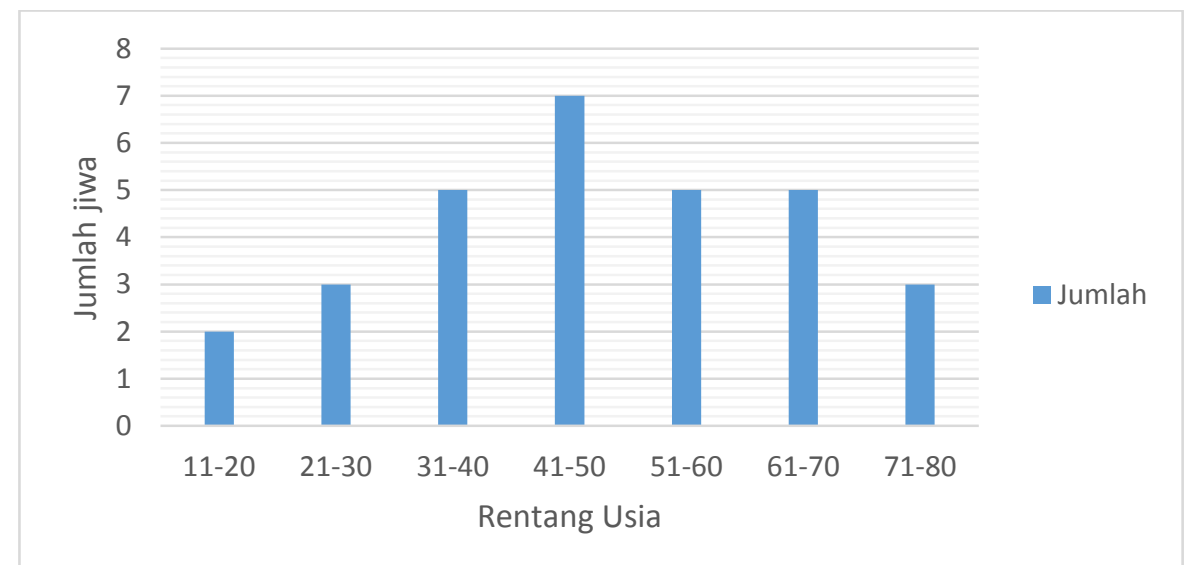

Gambar 6. Rentang Usia terhadap Jumlah Jiwa dalam Pengetahuan Masyarakat pada budaya Ngalaksa

\begin{abstract}
Rentang usia masyarakat mempengaruhi tingkat pengetahuan. Berdasarkan hasil yang didapat bahwa pengetahuan masyarakat terhadap budaya Ngalaksa sangat tinggi pada orang tua, khususnya bagi yang ikut andil dalam budaya Ngalaksa. Gambar 6 menunjukkan pengetahuan tertinggi sebanyak 7 orang berada pada rentang usia 41 hingga 50 tahun dengan tingkat kurang tahu. Sedangkan pengetahuan terendah sebanyak 2 orang pada rentang usia 11 hingga 20 tahun. Pada tingkat remaja sendiri pengetahuan dan keingintahuan terhadap budaya Ngalaksa sangat rendah karena masih belum mengerti dan acuh terhadap budaya. Oleh karena itu perlu adanya dorongan dan pengetahuan budaya Ngalaksa, khususnya proses membuat laksa, kepada generasi penerus supaya budaya Ngalaksa tetap terjaga.
\end{abstract}

\section{KESIMPULAN}

Ngalaksa adalah proses membuat kue laksa, yaitu makanan seperti lontong, sebagai budaya yang dilakukan oleh masyarakat Rancakalong sebagai ungkapan rasa syukur terhadap kemakmuran yang diberikan oleh Dewi Sri. Pemanfaatan padi (Oryza sativa L.) khusus varietas ranggeuyan ceresisi dan hawara, serta jenis tumbuhan lainnya yang tidak bisa digantikan dengan jenis tumbuhan lain menunjukkan tingkat ketergantungan budaya yang tinggi Pemenfaatan tumbuhan dalam budaya ngalaksa melalui budidaya dapat diartikan sebagai upaya pelestarian.

\section{UCAPAN TERIMA KASIH}

Ucapan terimakasih penulis sampaikan sebesar-besarnya terutama kepada orang tua penulis atas dukungannya dalam penulisan artikel, secara moril maupun materiil, Bapak Sahidin Ibnu Rusyid atas bantuan di lapangan, Polsek Rancakalong yang telah memberi informasi, dosen biologi, rekan Angkatan Rausyan Fikr, dan rekan kelas etnobotani 2019 Jurusan Biologi Fakultas Sains dan Teknologi, UIN Sunan Gunung Djati Bandung.

\section{DAFTAR PUSTAKA}

Andriansyah, M. (2012). Perancangan Buku Mengenai Simbol-Simbol Upacara Adat Ngalaksa. UNIKOM.

BPS Kabupaten Sumedang. (2018). Kabupaten Sumedang Dalam Angka Sumedang Regency in Figures 2018. Sumedang: BPS Kabupaten Sumedang. Irawan, B., \& Purbayanti, K. (2008). Karakterisasi dan Kekerabatan Kultival Padi Lokal Di Desa Rancakalong, Kecamatan Rancakalong, Kabupaten Sumedang. Seminar Nasional PTTI, 
21-23.

Isnendes, R. (2013). Struktur dan Fungsi Upacara Ngalaksa di Kecamatan Rancakalong Kabupaten Sumedang dalam Perspektif Pendidikan Karakter. Universitas Pendidikan Indonesia.

Isnendes, R. (2019). Ngalaksa in the Folktales of Rancakalong, Sumedang, West Java: A Local Historical Study. Tawarikh, 10(2), 157-172.

Komarudin, D. (2016). Makna Teologis pada Simbolisme Upacara Ngalaksa Terhadap Keberagamaan. Bandung: UIN Sunan Gunung Djati.

Mutaqin, A. Z., Noviani, E., Partasasmita, R., \& Iskandar, J. (2016). Studi etnobotani pemanfaatan jenis-jenis tumbuhan yang digunakan sebagai obat oleh masyarakat Desa Pangandaran Kecamatan Pangandaran Kabupaten Pangandaran. Prosiding Seminar Nasional MIPA 2016, 55-61.

Naufalin, R., \& Rukmini, S. (2014). Potensi Bunga Kecombrang Sebagai Pengawet Alami Pada Tahu dan Ikan. Seminar Nasional Pusat Penelitian Pangan, Gizi, Dan Kesehatan, (October 2010).

Setiawan, H., \& Qiptiyah, M. (2014). Kajian Etnobotani Masyarakat Adat Suku Moronene Di Taman Nasional Rawa Aopa Watumohai. Jurnal Penelitian Kehutanan Wallacea, 3(2), 107-117.

Sugiyono, S. (2007). Metode Penelitian Kualitatif Kuantitatif dan $R \& D$. Bandung: Alfabeta.

Sumedang, P. K. (2018). Geografi. Retrieved December 25, 2019, from http://www2.sumedangkab.go.id/index. php?class=profil_geografi 